\title{
MALE SOCIAL WORKERS: THE EXPERIENCE OF MASCULINITY IN "FEMALE" WORK
}

by

Michael Dionisi, BSW Lakehead University 2012

\author{
An MRP \\ presented to Ryerson University
}

in partial fulfillments of the

requirements for the degree of

Masters of Social Work

in the Program of

Social Work

Toronto, Ontario, Canada, 2014

(C) Michael Dionisi 2014* 


\section{Author's Declaration}

I hereby declare that I am the sole author of this MRP. This is a true copy of the MRP, including any required final revisions.

I authorize Ryerson University to lend this MRP to other institutions or individuals for the purpose of scholarly research.

I further authorize Ryerson University to reproduce this MRP by photocopying or by other means, in total or in part, at the request of other institutions or individuals for the purpose of scholarly research.

I understand that my MRP may be made electronically available to the public.

Signature 


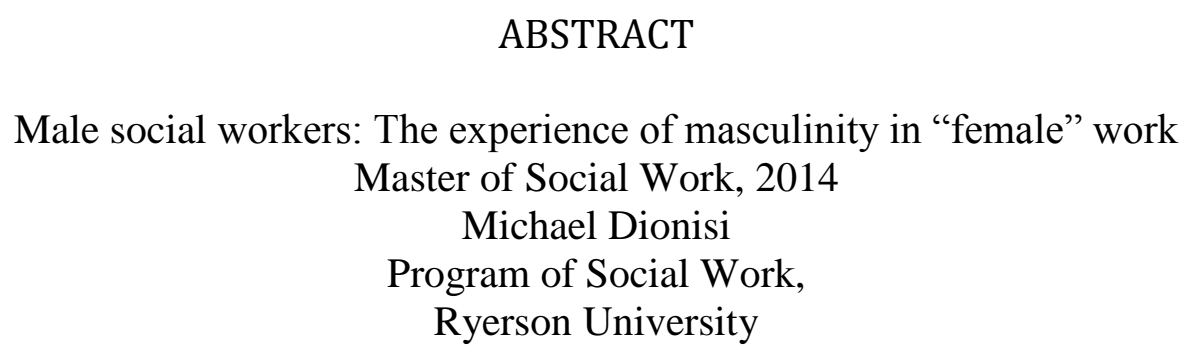

This MRP explores the experiences of male social workers working within the female dominated profession of child protection. More specifically, it was the goal to examine a) the potential obstacles that male social workers face as a result of hegemonic constructions of masculinity; b) whether these men use their position as a site of resistance to the patriarchal social order; and c) whether workplace dynamics further perpetuate patriarchy. Using the narrative approach three male social workers were interviewed. These co-researchers indicated that they experienced difficulties building rapport and engaging with clients, and expressed challenges regarding how they are perceived. They also explained that being a male social worker can have some privileges when it comes to interacting with male clients and being given more authority in their roles. When taken together, it becomes clear that patriarchal ideals and assumptions are alive and well within the context of child welfare. 


\section{ACKNOWLEDGEMENTS}

I would first like to thank the three men who participated in this research. This project would not have been possible without your insights. I am very grateful to know that there are people like you advocating for children and their families. To all my professors, Dr. Yee, and my research advisor, Dr. Henry Parada, I feel very fortunate to have been guided by your expertise and passion for anti-oppressive social work. I have learned a great deal from you and your courses and look forward to applying these lessons in my future work with others. I would also like to thank all of my friends who kept me laughing throughout the stressful process of obtaining a Master's degree, and reminding me of the importance of work-life balance. To my family, you have always supported my decisions, and offered your love, thoughts, and prayers when I needed them most. Thank you for the continued encouragement to see my goals through. Leah, I am very blessed to have you in my corner. Thank you for supporting me and my decision to return to school, and for making the many sacrifices that came along with that. Here's to our next adventure! 


\section{DEDICATION}

A Never-ending Gift - your support, selflessness, and guidance has meant so much to me

throughout this process. I am forever thankful to have you in my life, and know that without you this dream would not likely have become a reality. You are my hero! Thank you! 


\section{TABLE OF CONTENTS}

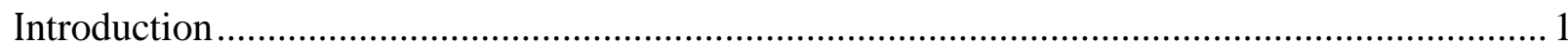

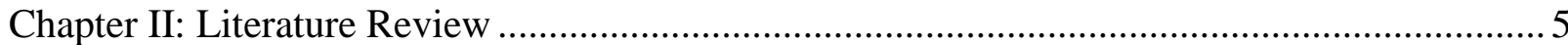

Chapter III: Methodology / Research Design ..................................................................... 13

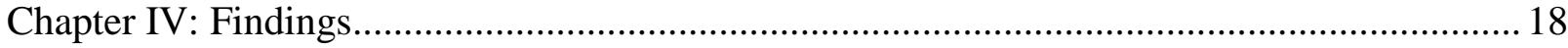

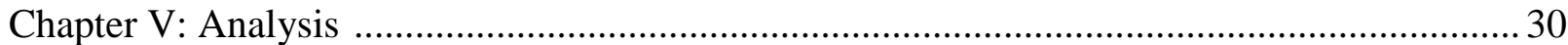

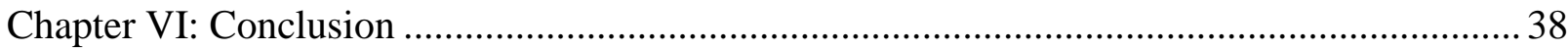

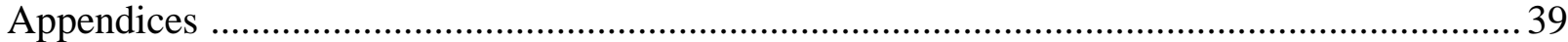

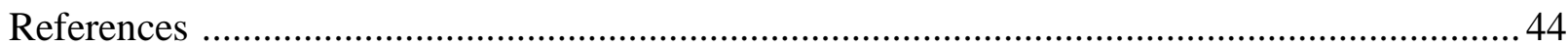




\section{LIST OF APPENDICES}

Page

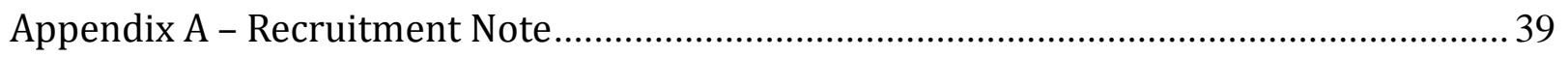

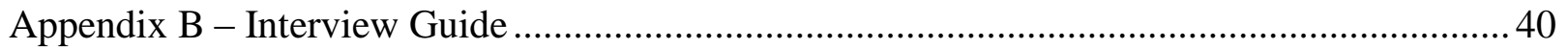

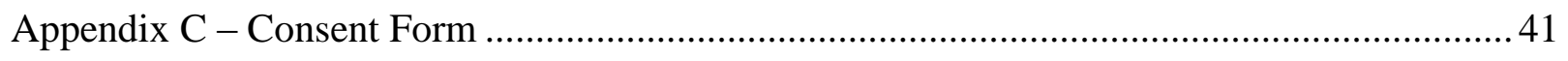




\section{Chapter I : Introduction}

Male social workers are in the minority (Christie, 2001). When considering the social construction of caring professions in general, and social work in particular as "female work" (Gillingham, 2006; Glick, Wilk, \& Perreault, 1995; Poole \& Isaacs, 1997), this gender imbalance is not surprising. However, given men hold minority status within this occupational context, one wonders how the experiences of this demographic may differ from their female counterparts, and how the constructions of masculinity that dominate in our patriarchal society, impact their working lives. As such, my Major Research Paper (MRP) explores the experiences of male social workers working within the female dominated profession of child protection (i.e. child protection workers). More specifically, this study looks at male social workers and how masculinity is experienced and enacted within this context. First, I will seek to determine if residing in a subordinate masculine role by virtue of their female occupation, results in challenges for these men at work as they interact with their colleagues, clients, and supervisors. Second, I will explore whether these men use their non-hegemonic position as a site of resistance to the patriarchal social order - for example, by the conscious act of joining a "female" profession or by vocalizing their rejection of male stereotypes communicated to them by those in the environment. Finally, determining whether their workplace dynamics in fact further perpetuate larger hegemonic ideals or patriarchy will also be considered.

When it comes to the motivation behind my research, and implicating myself within it, I draw upon my recent experiences as a full-time child protection worker. It is through this experience that I developed curiosities and concerns about my topic of interest. During this time I had seen how ideals of masculinity are at play both inside and outside of the agency, and the impact that such conceptualizations can have on workers and clients. For instance, in my own 
experiences as a male social worker charged with handling a file involving domestic violence, issues of client trust became an apparent concern. Furthermore, being regularly sought out by coworkers to accompany them on cases specifically involving high risk or volatile situations (i.e. where "muscle" was required) is something that I became accustomed to. It is experiences such as these that have motivated me to explore why these dynamics exist, and how gender roles and stereotypes impact, and are affected by, the various interactions and experiences of male social workers.

As the role of masculinity in the experiences of male social workers has not been explored previously, this research project has the potential to contribute to the current literature on males in caring professions. While we know that males employed in other variants of femalework (i.e. male nurses) often have negative workplace experiences (Hsu, Chen, Yuh, \& Lou, 2010; Rajacich, Kane, Williston, \& Cameron, 2013; Sumsion, 1999; Tankha, 2006), and have some knowledge about why male social workers choose to enter this profession (Rajacich, Kane, Williston, \& Cameron, 2013; Soerlie, Talseth, \& Talseth, 1997; Sumsion, 1999; Whittcock \& Leonard, 2003), we do not know how male gender roles and masculine stereotypes are experienced, enacted or opposed within the female dominated workplace of child protection. As such, my MRP focuses on an original set of questions. Further still, as the majority of research to date has taken a quantitative approach to the topic of male employees in female professions (e.g. Loughrey, 2007; Migliaccio, 2009; Tankha, 2006; \& Thompson \& Pleck, 1986), the qualitative approach that I am taking demonstrates a unique strength and addition to the literature. Further, as my review of the literature suggests that the majority of research conducted on males in "female" work has been undertaken by women, the fact that I am a male researcher may be an additional strength of this study. As it has been suggested, discussions between males and 
females may actually produce different results than between same-gender individuals (e.g., William \& Heikes, 1993). This effect may be particularly strong when considering the topics addressed in this study. Thus, my own maleness may foster beneficial conditions for male participants when it comes to them sharing their lived experiences.

From a practitioner's point of view, it is important to not only recognize the construction of masculinity within the social work profession, but also how gender roles and stereotypes (either consciously or unconsciously) affect social workers and clients. As such, by conducting this research that will reveal some of the specific ways that conceptions of masculinity may impede the effective provision of services, a better understanding of the steps that can be taken to address these issues, and where we can direct interventions, will be achieved.

Finally, in line with the AOP approach, this research strives to ensure that those participating will benefit from this study (Potts \& Brown, 2005). One way this research accomplishes this goal is by creating an open dialogue and safe space wherein male social workers can share their perspectives and experiences. In so doing, the voices of a group that has not been given much attention in the past are heard. Given the hegemonic, patriarchal nature of our society (Connell, 1995; 2000), conceptualizations of masculinity and the experiences of males in light of gender norms and stereotypes are often taken for granted or pushed aside. By acknowledging these issues, and providing the opportunity for men to discuss any experiences they desire, this study shows these men that they are not alone in working through the issues that "masculinity" may present when working in "female" jobs. This research will also provide a foundation upon which further research on the issue of gender roles and masculinity in social work can be conducted -- possibly with a focus that will be enriched by the perspectives of other groups (i.e. clients, racial minority males, female coworkers etc.). 
The following chapters will shed light on the lived experiences of several male social workers employed in the area of child protection. In Chapter 2, I first provide a comprehensive literature review on research that has been conducted to date on males working in femaledominated profession, and where possible, those that specifically focus on male social workers. I then outline pertinent concepts (e.g., gender roles, patriarchy) and the theoretical lens through which this research has been developed. Chapter 3 provides a discussion of the methodology and procedures used to examine the experiences of three male child protection workers, followed by Chapter 4 that identifies the common themes that emerged through the interviews with these men. Finally in Chapter 5, a review of my findings, their implications, and directions for future research are discussed. 


\section{Chapter II : Literature Review}

This chapter will review previous literature that has explored the issue of males employed in "female work" more generally, and males employed in the social work profession specifically. Following this, discussion of several important concepts to the current study will be reviewed, including "masculine" and "feminine" work, gender roles and stereotypes, and hegemonic masculinity. This chapter will then conclude with a review of critical masculinity theory and how its principles are applied in this research. Importantly, it should be noted that my own identity as a white, heterosexual male social worker may have influenced the interpretation of the literature provided below. While I have done my best throughout this review process to critically reflect upon how my own positionality may impact my understandings and selection of this literature, I am conscious of the biases which may impact this research.

The current literature review entailed a scan of many peer-reviewed journal articles. Databases reviewed included ProQuest from Ryerson University, Lakehead University, and the University of Guelph, and a variety of search terms including 'men', 'male', 'gender', 'masculinity', ‘femininity', 'critical masculinity', hegemonic', 'patriarchy', 'social work', 'social service', 'nurse', ‘stereotypes', ‘gender role', 'gender norm', ‘backlash', 'exclusion', and 'acceptance' were used. While the focus of this MRP is on the experiences of males in the social work profession specifically, my review of the literature revealed that in line with calls put forward for more research focusing on male social workers (Gillingham, 2006), there are very few studies that have looked at this topic. There was, however, a relatively large body of literature exploring the experiences of men working within female-dominated or caring professions more generally. Thus, given the parallels between the over-arching themes of this MRP (e.g., how masculinity is experienced and enacted within this context; how gender roles 
and stereotypes affect men in the "female" profession of social work) and those explored in research looking at men and masculinities in "female work" more generally, studies such as these were not excluded from this literature review. The majority of the studies summarized below are empirical in nature, employ either quantitative or qualitative methodologies, and draw upon data collected in several countries.

\section{Masculine and Feminine Jobs}

Based on the idea that men and women are characterized by different (gender-based) traits and temperaments, it is also commonly assumed that men and women are better suited to fulfill certain occupational roles within society (White \& White, 2006). For example, as gender stereotypes dictate that women are compassionate, warm, and nurturing, it follows that women should also be more successful at jobs that require these characteristics (for example, nursing or teaching). Conversely, as men are thought to be more assertive, rational, and strong compared to women, so too should they make better law enforcement agents, construction workers, or engineers, jobs for which characteristics such as these are thought to be important (Glick, Wilk, \& Perreault, 1995; White \& White, 2006). Therefore, certain occupations come to be socially accepted as "masculine" or "feminine" in nature, and as a result, tend to attract more men or more women (respectively) to these positions, ultimately creating workplaces that are almost totally dominated by one sex (Cejka \& Eagly, 1999). It is these skewed sex-ratios that not only perpetuate the idea that a particular job is gendered (Beggs \& Doolittle, 1993; Shinar, 1975), but also reinforce gendered-based expectations for behavior within these jobs (Glick, 1991).

Given the gendered nature of many jobs, previous research has explored whether those who join occupations that are not aligned with their gender, encounter any challenges as a result. To this end, research has shown that women employed in masculine professions experience 
higher levels of stress (Mansfield, Koch, Henderson, Vicary, Cohn, \& Young, 1991), and are often the victims of sexual harassment and aggression (Fisk \& Glick, 1995; Smith, 2013). Further, women in male-dominated professions also experience discrimination of various kinds, including when it comes to their salary (Ashraf 2007; Hick 2012), promotion and training (Smith, 2013). Given the powerlessness of women relative to men in a patriarchal social system (Courtenay, 2000), it is not surprising that females entering into "men's work" experience pushback and mistreatment. However, one must question whether men (who hold positions of power in society) experience similar consequences when employed in "female" professions? - a question which brings me to the focus of this study.

To date, the majority of empirical research exploring issues concerning males in "female work" (Poole \& Isaacs, 1997) has focused on one of several themes: the disproportionate experience of aggression and mistreatment for these men, their unique pressures or stress, their motivations for joining such professions, and issues pertinent to gender norms and stereotypes. Aggression and Mistreatment Against Males in Caring Professions

Previous research investigating the experiences of males in caring professions has demonstrated the vulnerability of these workers to various forms of mistreatment. Studies by Newhill (1996) and Ringstand (2005) for example, explore the issue of client-enacted aggression against social workers, examining in detail the extent, nature and impact of client violence on these employees. As their findings reveal, male social workers are likely to experience client violence at higher rates than their female counterparts, and that the aggression experienced often takes on both psychological and physical forms. Both researchers suggest that higher rates of aggression enacted against male compared to female social workers is due in large to the social work contexts that men work within, and the roles in which they inherit (i.e. male social workers 
tend to work in corrections, school settings, and child protection). Aggression has also been examined with male nurses, and similar findings have been produced. Exploring gender differences, Andrews, Stewart, Morgan and D’Arcy (2012) found evidence supporting the vulnerability of men within the nursing profession to workplace aggression. Once again, studies suggest that the elevated rates of aggression experienced by male nurses can be explained by the roles men fulfill in this profession, as they are often required to work with more violent clients (e.g., patients in psychiatric wards) (Arntez, Arnets, \& Petterson 2007).

\section{Male Pressures and Stress}

In addition to examining heightened mistreatment and aggression, previous research has also explored the unique workplace pressures and stresses that accompany being a male in a female-dominated profession. For instance, in a study by Tankha (2006), men were found to experience higher levels of role stress (e.g., job overload, role ambiguity, role isolation, resource inadequacy) compared to their female peers. A number of previous studies (Hsu, Chen, Yuh, \& Lou, 2010; Rajacich, Kane, Williston, \& Cameron, 2013; Sumsion, 1999) have also looked at what is contributing to these elevated levels of stress among male social workers, nurses and childcare workers. Findings suggest that this stress is reportedly due in large part to role conflicts (Hsu, Chen, Yuh, \& Lou, 2010) and gender-based stereotyping and norms (Rajacich, Kane, Williston, \& Cameron, 2013; Sumsion, 1999). While the connection is not explicitly investigated in these studies, the stress experienced by males in caring professions may also be due to issues associated with peer acceptance, as previously identified by researchers (Fottler 1976;

McMillian, Morgan, \& Ament 2006).

\section{Career Motivations}


An additional theme examined within the literature on men in caring professions looks at career motivations and why men are choosing to pursue what is deemed to be "women's work" (Sumsion, 1999). Evidence suggests that a main factor in this decision comes from one's family structure. More specifically, research has shown that males who took on caring roles within their families when they were young, those who come from single-parent families (Soerlie, Talseth, \& Talseth, 1997), or those who had family members or friends working within the healthcare system (in the case of male nurses; Rajacich, Kane, Williston, \& Cameron, 2013; Whittcock \& Leonard, 2003) were more likely to see this career as a personal possibility. Conversely, Lupton (2006) suggests that the pursuit of a career within nursing has little to do with family life, but that social mobility and opportunities to advance within a gendered labor market are more significant contributors.

\section{Gender-Based Expectations}

The existence and impact of gender roles and stereotypes on male social workers, nurses, and/or childcare workers was also a theme in the literature reviewed. More specifically, articles (Loughrey, 2008; Meadus, \& Twomey, 2001; Yang, Gau, Shiau, Hu, \& Shih, 2004) emphasized how such professions are often seen as female work within today's society, and as such, present unique gender-based challenges for the males within them. Loughrey (2008) and Yang, Gau, Shiau, Hu, and Shih, (2004) for instance, spoke of how their participants identified that their work in nursing typically mirrored that of female gender roles. In addition, treatment from coworkers and patients were also examined. Male nurses said that they were challenged by these outsiders as to why they were performing this work, and whether this was reflective of the fact that they could not complete jobs that were more masculine (Meadus \& Twomey, 2001), or was rooted in issues associated with their sexuality (Yang, Gau, Shiau, Hu, \& Shih, 2004). Literature 
also revealed that men working in female-dominated positions were often forced by organizational authorities or other coworkers to fulfill more masculine roles within their jobs, such as becoming the male father figure and participating in more male activities (i.e. playing with trucks; Murray, 1996), and were encouraged to pursue more supervisory positions (Zelek \& Phillips, 2002).

The notion that gender roles and stereotypes influence the experiences of males working within "female" professions, is one that is particularly important and central to the current study. As such, a review of these concepts is now provided.

\section{Critical Masculinity Theory: Gender Roles and Hegemonic Masculinity}

Gender roles represent a set of expectations about how men and women ought to behave, and the roles that they should fulfill in the home, the workplace, and wider society (Connell, 1995; Heilman 2012). Originally stemming from the idea that men and women are biologically different, and as such, are naturally better suited to take part in, and perform certain tasks and responsibilities (i.e. female childbearing and rearing; male breadwinners) (Wood \& Eagly, 2002), gender roles are now understood to be a socially constructed phenomenon. More specially, while being "male" or "female" is still connected to a specific set of gender-based expectations for behavior, the larger social system is said to create and perpetuate these ideals, through socialization processes and many of its institutions (Connell, 1995; Kimmel, 1995; Pleck, 1981; West \& Zimmerman, 1987). Further still, coupled with these gender roles are specific characteristics (i.e. stereotypes) that are thought to be embodied by "men" and "women" by virtue of their sex. For example, according to gender stereotypes men should take on assertive, dominant, and competitive traits, whereas women should be more communal, compassionate, warm, and expressive (Bem 1981; Heilman, 2012). Importantly, the notions of 
"masculinity" and "femininity" are said to be the internalization of these socially constructed gender roles (Connell, 1995).

Over the years scholars have come to recognize that while gender role theory would lead us to believe there is one masculinity (and femininity), in reality masculinities are multiple in that various identities (race and gender; sexuality and gender; profession and gender) intersect (Connell, 1995). However, there is still a dominant ideology of masculinity that is ultimately applied to all men as the expectation that they are to meet (Scott-Samuel, Stanistreet, \& Crawshaw, 2009). Otherwise known as hegemonic masculinity (Connell, 1995), this ideology (which today characterizes masculinity by attributes such as aggressiveness, toughness, a lack of emotion, and individualism) (Scott-Samuel, Stanistree, \& Crawshaw, 2009) works to ensure that men are behaving in specific ways that serve to secure their positions of dominance over others. As such, hegemonic masculinity feeds into the patriarchal social system that dominates in our culture - one where males have power over females at both individual and systemic social levels (Courtenay, 2000). Further, by highlighting the existence of a gender hierarchy among men (certain men are better than others) hegemonic masculinity also showcases how certain men (white, heterosexual, upper class; those who fit the ideal traits above), maintain power and positions of domination over other men (i.e. racialized, homosexual, impoverished, those who display "feminine" traits) (Connell, 1995).

Critical masculinity theory suggests that those who do not fit the dominant ideal of masculinity within society may face barriers and obstacles given their position of subordination within the gender hierarchy among males (Connell, 1995). Thus, when applied to the current context, male social workers - who by virtue of their enactment of a female role through their profession - may similarly encounter challenges. Indeed, previous research exploring the 
backlash effects - or the social and economic reprisals for behaving counter-stereotypically (Rudman, 1998) - suggests that those who violate gender norms and stereotypes may face mistreatment, discrimination, or other kinds of obstacles. For example, studies exploring harassment towards homosexual (Parrott, 2009) and even heterosexual men that do not fit hegemonic ideals of “proper” masculinity (Berdahl, Magley \& Waldo, 1996), shows how aggression may be used to punish these individuals. Studies also show that males in counternormative positions may experience pushback from peers and coworkers (Meadus \& Twomey, 2001; Yang et al 2004). Importantly, however, critical masculinity theory also maintains that through the enactment of non-hegemonic masculinities (i.e. those that do not align with dominant standards), the male-dominated gender order can be undermined (Connell, 1995; Wedgewood, 2009).

Contributing to critical, transformative AOP practice, it is my belief the concepts and ideas ultimately demonstrated and drawn from this research may help to shine a light on how societal expectations of masculinity not only create obstacles for men themselves, but may also foster conditions within the social work profession that serve to reinforce patriarchy. The more that men are discouraged from entering the field of social work, and male social workers themselves are discouraged from occupying frontline positions (and possibly redirected to either management roles or other careers as is highlighted by other research addressing male social workers; Gillingham, 2006), the more the notion that caring professions are "female work" is reaffirmed, and thus so to, the gender roles and stereotypes that support patriarchy. However, if it is found that male social workers seek to dismantle these stereotypes through their counternormative role, this research will also highlight a previously unacknowledged avenue through which gender oppression on a larger social scale is / can be addressed. Thus, it is my hope that 
this project will not only reveal the lived experiences of male social workers, and the role of masculinity in these experiences, but also contribute insights that can be used to combat gender oppression more generally. 


\section{Chapter III : Methodology / Research Design}

This chapter will focus on the research design of this study. First, a description of the narrative approach used to capture the experiences of participants will be provided, followed by a discussion of the benefits associated with this approach. Second, information is provided about the individuals who participated in this study. Finally, a description of the procedures used is given.

The Narrative Approach

This study implemented a qualitative narrative approach, whereby participants were given the opportunity to tell their own stories and dig deeper into the experiences that they believed were relevant and central to the issue of being a male in the "female" profession of child protection. By fostering a collaborative conversation between the researcher and participant, where only overarching themes are provided as a loose format for the discussion, the narrative approach allows for a richer, more individualistic exploration of participants' stories 3 (Larsson \& Sjöblom, 2010).

While the majority of research to date has taken a quantitative approach to the topic of male employees in "female" professions (e.g., Loughrey, 2007; Migliaccio, 2009; Tankha, 2006; Thompson \& Pleck, 1986), quantitative methodologies are limited in the type of information that participants can share. For example, when using survey based methodologies with specific answer choices, participants are unable to give context to their answers, elaborate on their responses, or provide important information that may not fall into any of the response choices given. Further still, this methodology requires participants to select between pre-determined "realities" that are imposed upon them by the researcher (Chilisa, 2012).

In contrast, the narrative approach allows for more flexibility in the research process, 
enabling participants to discuss the issues/topics they feel are most relevant in regards to the question of concern. In so doing, the narrative allowed me to give voice to my male participants (Larsson \& Sjöblom, 2010) potentially using their experiences to challenge dominant social practices (Fraser, 2004). The narrative approach is also particularly useful when studying issues concerning identity, as well as stories told by minority or counter-normative groups in society, given this approach can reveal issues and ideas that may not be immediately apparent or familiar to those belonging to majority groups (Larsson \& Sjöblom, 2010) - issues of obvious concern to the current study. Finally, the narrative approach offers an opportunity for the researcher to be the "learner" as opposed to the "expert", and in so doing, diminish any power imbalances that may have been fostered by virtue of authoritative interviewer position (Potts \& Brown, 2005).

Given that being male is associated with power and control within mainstream society, the need to give a group of males voice, may seem counterintuitive. However, within the specific context of child protection men occupy a minority position, and in the eyes of the public may be seen as inferior representations of the male gender given their violation (by virtue of their chosen "female" profession) of hegemonic masculine ideals and the patriarchal social order. Thus, this population arguably represents a unique group of men with potentially unique stories to share stories which can best be captured using the narrative approach. Moreover, in line with critical masculinity theory, as masculinities are multiple (i.e. various social identities interact with gender) and there exists a gender hierarchy among men (Connell, 1995), the narrative approach is particularly critical, as it can allow each unique male voice to be heard, and can reveal any commonalities and/or differences that may exist in light of male child protection workers' individual uniqueness. 


\section{Participants}

Three male social workers actively working in the field of child protection were recruited for this study. All participants were 18 years of age or older, and working full-time as a frontline worker (i.e., intake, family service, or child protection worker) in larger, urban social work agencies. It was important that the participants are frontline workers and not supervisors or managers, to ensure that they are actively involved and interacting with coworkers and clients daily. Additionally, supervisory positions are typically seen as 'masculine', which is not the purpose of investigation in this study. Participants had no other known special characteristics.

\section{Procedure}

Purposive snowball sampling was used to recruit male social workers working within various child protection agencies in southern Ontario. As a previous child protection worker, I was able to use my contacts to begin the recruitment process through email. Requests were made of these individuals to distribute this study's recruitment notice (Appendix A) to their male coworkers. If a male social worker was interested in participating in this study, we determined a mutually agreed upon meeting time and place.

Participants took part in a one-time, one-on-one interview that lasted between 20 and 30 minutes. After reviewing and signing the Letter of Information and Informed Consent form (Appendix B), I opened each audio-recorded interview by asking the question:

"What have your experiences been like being a male social worker in the profession of social work / child protection?"

Participants were asked to respond to this question, and then to continue sharing their stories and experiences about being a male social worker, as they saw fit. When faced with points of extended silence, I proceeded to encourage participants with additional general questions, again letting them guide the discussion as they wished. Any conversation that 
continued after the audio-recorded interview had ended was documented using hand-written notes.

In effort to address relationships of power within the research process, and to ensure that I am accurately interpreting the information I received from participants, research subjects were included in the data analysis process. More specifically, I shared a summary of main points taken after each interview with each participant. When desired, I also allowed my participants to listen to the audio recording from their own interview. In so doing, I hoped to reduce power imbalances by elevating participants above mere "subjects" (a subordinate position) to "coresearchers" (a position of equality) (Chilisa, 2012). In addition, to ensure that the voices of my participants are represented to the best of my ability, I was in contact with the male social workers prior to my submission of the final copy of this MRP to verify that my personal biases and own subjectivity had not altered the meaning of what they shared. In so doing, I could better ensure that they were comfortable having this information (while anonymous) submitted to others. Moreover, by involving co-researchers in this way, power and control were transferred back to these men by giving them the opportunity to ensure that their portrayal was accurate and authentic.

All interviews were transcribed verbatim, and language is presented just as it was communicated to ensure that the spirit of the conversation was accurately captured. These transcripts were then reviewed. I looked for evidence of common themes that emerged from the data derived from this group of male child protection workers. I coded the text according to these themes and compiled notes based on them. The themes are discussed in greater detail in the following chapter. 


\section{Chapter IV : Findings}

This chapter will present the findings derived from my interviews with three male child protection workers. More specifically, out of my conversations with these men, 2 major themes emerged, namely (a) the unique challenges faced by male child protection workers and (b) the unique position fostered by their gender as a site of resistance against hegemonic masculine ideals. In addition, where applicable any privileges associated with being a male in the field of child protection are presented.

While coming from different agencies, all three child protection workers worked in larger urban child welfare agencies in southern Ontario. Two of these men worked in the area of family services, while the other worked in crown ward. Occupational experience ranged from $2-10$ years. Participants were 26, 28, and 50 years old, and were all Caucasian.

\section{Challenges Faced by Male Child Protection Workers}

It seems that there are indeed a number of challenges associated with being male in the female dominated world of child protection. More specifically, the male child protection workers interviewed explicitly communicated difficulties associated with their interactions with clients, coworkers, and their social image, given their male gender.

\section{Difficulties with clients: Caregivers}

As a child protection worker, one is often responsible for engaging with the caregivers of at-risk children. In several cases, the male child protection workers indicated that interacting with female caregivers in particular, was a challenge given their maleness. As many of the women they work with have either a history of, or are currently involved in situations of domestic violence and/or sexual abuse at the hands of a man, they felt that their male sex created strong barriers to the development of trust and rapport. One child protection worker 
communicated concerns that being male may conjure up images in female caregivers, of the person who had victimized them:

I have no idea if I remind people of their father, their uncle, their cousin, the older guy in the neighbourhood - whatever. I don't know their story. I don't know what my image, or gender is in their mind. I don't know what they think... How do you overcome all the stuff that they had to go through with men-and I'm a guy showing up?

He went on to explain that a caregiver's hesitation and lack of trust for males can impact the assignment of cases, and result in male workers being passed over for files.

Sometimes you get clients who say they don't want a male worker because of their past, and they (agency) will take that into account.

Stereotypes that exist on a larger social scale also seem to be present in the interactions between male child protection workers and female caregivers. More specifically, workers expressed that their female clients at times project the stereotype of men as controlling and authoritative, onto the male worker. While this may no doubt be a reality for these women in the interactions that they have with other males in their lives, such projections no doubt impact the dynamics that exist between male workers and their female clients.

I met with a mom that had um, she was clean but she really hadn't dealt with her additions. Plus she had a history of sexual abuse by her family that really hadn't been dealt with. So then when I met her, the intake worker said "this is Xyou will be working with him, he knows what he's doing"..... And down the road she (client) said after the relationship came, she said "You know what I thought when I first saw you?" I said "what?". She said, "Another fucking guy going to tell me what to do." That was so humbling.

Moreover, one male child protection worker felt that female caregivers have at times, perceived him as a "male" (i.e. in a sexual sense) rather than as a professional trying to help her family. When this occurs, he suggested that these women may attempt to use their "femaleness" as a strategy during interactions with him, placing him in a awkward situation. 
The other thing is, women that traditionally haven't had a lot of power in their relationships, that haven't been successful negotiating with their partner, I notice that-you know, that she bends over to give me a little peak, and um, ... I notice that because I am a male they will use what they have used in the past with men. So I'm really aware of that and I'm thinking "geez, how do you overcome that one"

In my discussions with the male child protection workers, the recognition that their maleness creates barriers and issues for them when interacting with female caregivers was clear. These men not only shared their struggles interacting with these clients, but also seemed to be moved by them. As noted above, at least one worker felt "humbled" by such experiences, and the messages and symbolic meaning that his gender represents. Moreover, one expressed how "stuff (he) read about in the textbooks" pertaining to being a male, became a reality for him while on the job after several years.

\section{Difficulties with clients: Children}

While it is difficult for male child protection workers to interact with female caregivers, all of those interviewed also expressed the challenges they have when working with children. Given the past and present victimizing circumstances many of these young people face - most often at the hands of men - these workers found trust and rapport building difficult. Moreover, it also seemed to these workers that given the stereotypes in society, males are not always seen as being appropriate or well-suited to be serving in a caring role. As such, young clients often have difficultly confiding in them.

I find it is harder to engage with some children, as often the children that I am working with have been victim of sexual or physical abuse at the hands of a male caregiver. I find that establishing that initial rapport is a little more difficult because I think it's perceived as atypical for a man to be in a role where someone can confide in you and discuss their issues. I think that kind of ideals of patriarchy kind of permeates still moving forward with the generations. 
All of the workers also communicated difficulties when it comes to interacting with female children in particular. Once again, issues associated with victimization and male perpetration seemed to foster conditions of vulnerability that were counter-productive to healing. As one worker pointed out, overcoming such obstacles often requires the assistance of a female coworker.

I find that it seems that they (female child protection workers) have a much easier time with engaging the young girls pertaining to sexual abuse. They can get the children to talk and open up. I have not been able to do that with any of the young girls I work with. Often they will identify that they are not even comfortable, or that they don't feel safe disclosing this information to a male. That's a pretty rigid barrier I would say, in working with this population.

Moreover, the male workers also expressed the difficulties that they have dealing with female children given the types of issues that often need to be addressed with this population (e.g., menstruation). As these issues are more personally familiar to women, the male workers recognized that although capable, they may not be the best-suited workers to handle such interactions. They recognized that young girls may also themselves, prefer to interact with a female child protection worker. As such, it is not uncommon for these male workers to seek the aide of female coworkers or caregivers in such cases.

You know, girls get their period at that age. To me that doesn't bother me, but they would probably prefer talking to a girl about that. Or even if the girls have guy problems they would probably talk to a women about it.

I would talk to whoever plays the mother role in their life, so quite often there is the foster parent, the foster mom, who would have those kinds of conversations about the menstruation cycle. Or even like being on the pill, because a lot of girls 14 or 15 want to be on the pill. Pretty much at the end, it's not really about me, but its kid centered. So, like what will benefit this kid the most? I might be good in this kind of stuff, and the foster parent or someone else might be better at that role.

Importantly, it would seem that hegemonic notions of masculinity also infuse the relationships between male child protection workers and their young female clients. More 
specifically, larger societal portrayals of men as aggressive, violent, and sex-crazed, and women as weak and passive sexual objects, created conditions of significant tension for male workers working with female children - tensions which in fact, have materialized into legitimate threats impacting the way they must conduct their work. Given these stereotypes, the male workers communicated concerns about being alone with female children, for fear that the public would question their motives and the safety of said child. Moreover, given how commonly recognized these gender-based stereotypes are, these workers also communicated that young girls themselves have been know to use them to make false accusations of inappropriate conduct at the hands of male child protection workers. As a result, it has become customary in their organizations for men to bring along another coworker when conducting visits with young girls. Given such precautionary steps are strongly encouraged by organizations, this indeed seems to have become a systemic concern. The male workers also communicated frustration with the double-standard that appears to exist with regards to this issue, both in larger society as well as in their work environment.

I have been cautioned a few times by my supervisor: "X, you're going out with a young girl who is incredibly beautiful"... "I want you to try and never be alone with her" and "Do you think that's a good idea (to be alone with her) if you're transporting her somewhere" stuff like that. And my point has always been, do you talk like that to a female worker that is working with a teenage boy? Do you give them cautions?

It's kind of funny because a lot of female coworkers, they can talk to the guys about almost anything. Maybe there are a couple things they would prefer a guy to talk about, but overall I find it harder being a guy to talk to a female, because you know like, with society... I feel weird when I am driving a young girl somewhere. But like, a female coworker can drive men or females - whatever, it doesn't matter. So it's kind of funny that way.

The workers do acknowledge that such precautions are somewhat valid, however, given the vulnerable position that they are in given their sex. 
I think the risks for a male are higher. Not because of anything we do, it's just easy to make stories up. False allegations. And who knows probably some of them are true. I haven't hard anything here but...

While the difficulties communicated by these male child protection workers pertaining to their interactions with caregivers and children are no doubt many, the benefits of being male to these interactions were also raised during the interviews. These co-researchers were able to point to gender as an avenue to rapport building and commonality with male caregivers and children. Given their shared social identity with these clients, the male child protection workers felt they were advantaged when it came to such case files.

In working with fathers, particularly in instances of domestic abuse or sexual abuse I found it quite useful being a male because often I will see them justify to my female coworkers that the females wouldn't understand because "it's a male thing"

A lot of crown wards are young men. But in the crown ward unit there are only two, two guys (child protection workers). And so I have even noticed through my 8 months of being there that a lot of the boys prefer to have me as their worker, because they see women all in their live-some foster parents are just moms, there is no partner. So they don't have that positive male role model. So there is just some understanding. Kids like video games, I like video games. We just do our own kind of thing. I don't know, I find it's easier to relate to.

Difficulties with coworkers

The male child protection workers also discussed their interactions with coworkers, revealing that their maleness has at times impacted these relationships. One dynamic that was apparent and had the potential to be disruptive was rooted in the preferential treatment that one social worker expressed receiving from a supervisor, presumably (from his perspective) because he was a male.

As a man in the organization, I would say that it is quite different. A lot of the intricacies of the profession and operating within the workplace are different. In looking at interactions with supervisors, I find that there seems to be, at least in my experiences on my team, some underlying notions of patriarchy that still exist, where I am given the benefit of the doubt as oppose to my female colleagues.... 
For example if my supervisor were to provide a direction she believes that I should do following an investigation (whether it would be apprehend or mandate that the individual attend a certain service) I feel that, or it seems that, I am in the position to decline....And she will respect my opinion a little more over my other colleagues. And this certainly isn't something that is because of experience, as I have been there the least amount of time... She will go back and reflect on the suggestion and my perspective, as oppose to being very rigid as I have seen her with other workers.

He went on to describe how this impacts his relationship with coworkers.

On any given day I suppose the people on my team that are close to what is happening may be a little resentful of it. I can't see them being happy about seeing this kind of interaction. No one has ever said anything to her or myself. But I don't think they would ever feel like I am responsible or that it was something that I was trying to abuse.

While the worker did not believe his colleagues would hold him accountable for the unique treatment he received from his supervisor because he is male, this dynamic - which would appear to be apparent to many of those in the workplace environmental - is nonetheless notable. In addition, another male worker communicated that gender may play into differences of opinion between colleagues - a situation which he has encountered himself. As he explains:

The other thing about being a guy here is that I have been challenged by workers in here, female workers - I completely trust - and they will say " $X$, where the hell did you get that idea? What the hell are you talking about?" and then they will explain how they interpreted what I said.

In such cases, while still challenging, such dynamics between male and female workers may actually result in better care for clients.

Beyond the daily work requirements, it would seem that a divide exists for some male workers relative to their female colleagues. When asked to discuss their personal relationships with coworkers after hours, one co-researcher expressed the following:

I would say that I do have relationships with coworkers, but not that close. Often I just focus on my work when I am at work - there are high demands... I suppose that if I wished to be more engaged in it (relationships with coworkers), I know a 
lot of the female coworkers will band together and go out for their girls' night and stuff like that. And that is something that perhaps I wouldn't be included in.

When taken together, the gender of these male workers does seem to affect their interactions with coworkers in some way. Importantly, these men also expressed how much they respected their female peers, and have learned from them over the years. As one worker describes, "It was all females that showed me how to do this work. They're the ones that raised me, they're, showed me what it takes to be a child protection worker'. He went on to express his admiration for these women, and his gratefulness for the unique relationships he has with his female coworkers.

I don't think many men get a chance to have a relationship, a working relationship based on trust and understanding in the workplace with females. With women that are smart, bright, and won't take any crap, and they're courageous, and they're willing to challenge your ideas.

Difficulties with social image

Finally, there was some indication that these male child protection workers faced challenges with regards to the public perception of their identity, given their chosen profession. More specifically, in line with hegemonic masculinity, and the notion that "real men" are aggressive and dominant as opposed to caring and nurturing, these men felt that others in the environment often questioned their masculinity given the fact that they were violating these stereotypes. As one man explained:

I know that in the past there has been such assumptions with families. People assume for example that I am a homosexual. So I have a partner who is female, but I refer to her as "my partner" if I am having conversations with them. They default to the belief of homosexuality because of my career choice. So that seemed to be something that was surprising.

Moreover, another male child protection worker expressed the negative and discriminatory responses he often receives from male clients, when he behaves in a way or communicates 
opinions and beliefs that violate traditional notions of masculinity. For example, this worker notes that in such cases male caregivers "will call me a pussy, and ask me if I'm gay".

The prevalence of such gender-based stereotypes are also evident to these child protection workers in the way that people assume they hold authoritarian roles given that they are male. Moreover, these assumptions seem to be prevalent in both interactions with clients, as well as within the workplace.

I think men unofficially come off as more intimidating. I don't know. I don't know if well respected is the word, but I think there is this kind of like authority that just comes with it (being a man)- whether you like it or not...I've seen that too in my experiences with families. Being a male, I don't know, I just kind of notice. I find that the women that I work with, they kind of have to sometimes prove that they are authoritative...they get really into what they are saying, because Ifeel that they think that they need to dominate or whatever - I don't know.

I found that they (clients) assumed that I am not actually in the role I am, and that I am of higher importance, or higher authority by virtue of being male. I certainly see that working with immigrant populations - something that has sometimes come up. People have sought me out as an authority figure even when I was a student. For example I was going around watching an investigation with a worker, and the family assumed that perhaps I had some kind of stake or role to control the situation.

I went into a home once, and in the back there were the neighbours having coffee and cigarettes, and I'm watching. In the living room there are two police officers, there are 4 little kids running around, and there's a grandmother, and her daughter... and they are fighting. And I walked in and everyone shut up. And I thought-and I hadn't been here for that long, maybe 2 and a half years - shit, they think I know what I'm doing, and they all shut up - haha. And I took advantage of that. .... so I know being a male, especially like me, traditionally looking, older guy, people look at me and think I am an authoritarian male. They will think that I am very experienced and am kind of set in my ways. They will think I am strength... Their perception is the "strong". So if I want to have a relationship, a lot of the time you have to address a lot of those things.

The existence of these stereotypes is no doubt complicated for these male child protection workers. On the one hand, assumptions of their authority and experience could be used to their advantage when trying to communicate and encourage progress with their clients - a fact which 
is evidenced by the claim that this is something that one male worker has at times taken advantage of. It would also seem that such assumptions foster dynamics in the workplace that are more beneficial to men. It would appear that in at least some cases, these male child protection workers do not have to try as hard to "prove" themselves as their female coworkers. It should be noted, that such dynamics arguably contribute to and perpetuate a patriarchal social system in which men reside in position of authority, and are afforded power and prestige over women. Importantly, these workers do acknowledge that these power dynamics can create barriers to rapport building and trust with clients (as revealed above), and as such, what may appear to be privileges, may indeed pose detrimental challenges.

\section{Gender as a Site of Resistance}

My conversations with these male child protection workers revealed that while there are indeed many challenges and unique experiences associated with being a male employed in "female" work, occupying such a role also provided these men with the opportunity to use their non-hegemonic position as a site of resistance to the patriarchal social order. These men repeatedly expressed their efforts to reject stereotypical and damaging ideas of what it means to be a man, communicated to them by clients. Moreover, these male social workers not only rejected patriarchal notions by expressing their disapproval of these attitudes to clients, but so too took it upon themselves to correct and educate those who expressed them. These men consciously challenged gender-based societal norms and expectations that they saw as contributing to inequality and injustice.

With regards to his young clients, one worker reports:

I will ask them (male youth) ... are you having sex? "Yup". Do you have any condoms? .... sometimes they don't. If they don't I will say, what happens if you meet up with your girlfriend, are you going to have sex today, and he said "Were 
gonna". And I say, you don't have a condom, and he says, "Sucks to be her". You know it gives you an opportunity to provide condoms, but it is also a chance to have a talk around what it means to be masculine, and to be in a relationship at different stages of your life. And to say "sucks to be her" - it's wrapped right around that domestic violence piece. How they've been raised to treat women and the words they use to describe their girlfriends. You try to challenge that. You do challenge that.

Similarly, helping sexual minority youths understand their masculinity and male identity

was also expressed as a valuable opportunity by one worker:

With gay youth too, part of it for me is, how do you express "I know that you are gay but you are also masculine. You are a male"... because I know that some of them think - "I can't do this because I'm gay". But they don't understand because it's their perception of being gay... A lot of men won't embrace ideas or feelings that they believe are feminine because they can't. In time they might, but where they are right now they can't. So it's a skewed masculinity in their mind.

One male child protection worker also emphasized how he often tries to talk to his young female clients about what it means to feel "safe and secure" with their boyfriends, and how they can "have a voice". Moreover, these child protection workers attempt to resist the patriarchal social order by empowering and educating female clients, attempting to give them agency.

In domestic abuse situations, I certainty don't want to go in a be perceived as being heavy handed, and kind of perpetuating further the power imbalance between the men in their (females) lives. I try in contrast to empower them more, improve their self-esteem if at all possible.

At the same time, educating male caregivers who possess damaging, hypermasculine ideologies is an expressed priority for these workers. One worker explained that he finds value in being able to confront justifications for violent behavior based on being a man "head on", saying “No this isn't something I do as a man". Another similarly explained the importance of not condoning or reinforcing the behaviour of violent male clients.

You want to hear their (domestic violence perpetrators') story, but at the same time you don't want to collude with them. You don't want to collude and say "Ya I understand, I know she's a bitch, I hear your story". Cops will do that just to get everyone calm. They'll say "Ya buddy, fuck I'd do the same thing." And it's just 
to get the guy out for the night, calm him down. They don't mean it. But I can't do that.

He continued....

Its just not ethical. Plus the second I collude with the man, especially around domestic violence, how can I hold him accountable? Or help lead him to that? And it's a fine line, because you can come on really strong. The first time you can say, flat-out "I'm a feminist, I don't buy your story." But, you say it in a way he can hear it.

Interestingly, it would appear that in at least one case, not all male child protection workers similarly uphold progressive, counter-normative beliefs about gender. As one male coresearcher explained:

I've been in a domestic violence training, where a guy has said, "just because a guys beating his wife up, doesn't mean he doesn't love the kids" and I'm thinking ya, but if you really loved your children you would show them how to live in the real world; how to treat someone else. It's a learning experience.... That came from a male (social) worker. I was offended. I was just thinking "Man are you stupid and insensitive and everything else?" To speak those beliefs here

However, just as he and the other child protection workers expressed in the case of clients who communicated misogynistic and hyper-gendered ideals, circumstances such as this provided this worker with the valuable opportunity to challenge and educate fellow employees.

You get a chance to influence other men that work here, because there are some Neanderthals that hold oppressive views about women... So you have that chance to influence other men.

When taken together, it is clear that these male child protection workers are aware of the influence that their gender has within the context, and the opportunity it provides for them to directly and indirectly combat gender-based stereotypes and attitudes that perpetuate patriarchy. Thus, while this job has its challenges for the male sex, it would also seem that the ability to contribute to high-level social change is something that is possible, and actively pursued by these men. 


\section{Chapter V : Analysis}

While all of the workers interviewed communicated that they enjoyed their field of practice, I discovered that being a male child protection worker is not without its challenges. These co-researchers indicated that they experienced difficulties building rapport and engaging with some caregivers, as their gender seems to represent the image of "perpetrator" or "victimizer" for many of their female clients enduring situations of domestic and sexual abuse. Moreover, the traditional relationships of power that exist within the patriarchal social system also seemed to impact their interactions with these clients, as women often expressed to them that they saw the worker as "a controlling and authoritative man". Male social workers also expressed difficulty in speaking and interacting with female children. These challenges arose due to a number of factors, including the difficulty female children often had opening up to a male authority, the types of "female" issues often needing to be dealt with concerning these girls, and the larger social stigma surrounding men interacting with female children. In the case of the later, concerns about the safety of male child protection workers in the face of false accusations made by young clients, impacted the tangible ways that these co-researchers had to conduct their work (e.g., working in social worker pairs in some circumstances). While there were some indications that their maleness impacted relationships with coworkers (i.e. the response of coworkers to their preferential treatment, differences of opinion possibly as a result of gender, and personal relationships outside of work), the co-researchers also expressed their admiration for their female peers, highlighting what they have learned from them. Finally, these male child protection workers expressed challenges regarding how they were perceived by those in the social environment. These men indicated being questioned about their masculinity and challenged about their male identity. Being called derogatory names such as "pussy" for their 
counter-normative attitudes and behaviors, and having their sexuality questioned given their chosen profession, posed challenges when working with clients.

Notwithstanding these challenges, the male child protection workers interviewed also explained that being a male in a female dominated profession can at times have some privileges. As discussed by these workers, being a male was beneficial in cases involving male clients, given that male caregivers and children were often better able to open up to a male (compared to a female) authority. Moreover, largely as a result gender-based stereotypes, the gender of these child protection workers also brought with it perceptions (from both clients and work peers) of their authority, dominance, and position at the top of the hierarchy.

When considering these challenges and privileges, it becomes clear that patriarchal ideals and assumptions are alive and well within the context of child welfare. These men are perceived and responded to by those they interact with in ways that are aligned with hegemonic masculinity, and the belief that "manliness" is characterized by a specific set of traits - traits which reflect assertiveness, toughness, dominance, and aggression (Bem 1981; Heilman, 2012; Scott-Samuel, Stanistree, \& Crawshaw, 2009). That these patriarchal assumptions impact the interactions that male child protection workers have with their clients and coworkers is troubling for a number of reasons. First, that patriarchal norms and stereotypes appear to be impacting the extent to which female clients are able to trust and relate to their male child protection workers, suggests that the quality of care and service that can be provided to these women by men, is being compromised. Patriarchy creates and reinforces the power imbalance between females and males, and thus so too between female clients and male child protection workers. In so doing, patriarchy becomes a barrier to service and presents significant obstacles for male child protection workers seeking to provide aide to those in need. 
Second, while gender norms and stereotypes were prevalent in the interactions with clients, these co-researchers also highlighted how patriarchal assumptions could be seen in the way that coworkers and supervisors afforded them more autonomy and authority in their roles, given their gender. While perhaps occurring unconsciously, the reinforcement of oppressive gender-based ideologies in workplace interactions is particularly concerning, given that the field of social work is one that should be rooted in social justice and equality. That such dynamics seem to be occurring within this workplace suggests that this field is not immune to larger societal influences that are oppressive to women, and thus the need for everyday workplace practices to be questioned more closely.

Third, in line with previous research exploring backlash effects (Rudman, 1998) against those who behave counter-stereotypically (Berdahl, Magley \& Waldo, 1996; Meadus \& Twomey, 2001; Parrott, 2009; Yang et al 2004) male child protection workers were treated poorly in many cases (for example were called derogatory names by clients; typecasted) given their violation of patriarchal gender norms and stereotypes - both by virtue of their professional role and the attitudes and ideologies they expressed that run counter to current hegemonic masculinity. As such, it would appear that patriarchy not only impacts service provision, and may be perpetuated by the dynamics that occur within the child welfare workplace, but in the case of male child protection workers specifically, seems to be contributing to their own mistreatment. In line with critical masculinity theory (Connell, 1995), we here see a case where a certain group of men who do not fit the dominant ideal of masculinity within society, face barriers and obstacles given their position of subordination within the gender hierarchy among males. 
Importantly, critical masculinity theory also maintains that through the enactment of nonhegemonic masculinities the male-dominated gender order can be undermined (Connell, 1995; Wedgewood, 2009). Based on my interviews with these male child protection workers, this does seem to be the case. These co-researchers explicitly shared with me their conscious attempts to challenge oppressive and stigmatizing gender-based attitudes and behaviors. They expressed the value of being able to use their identity as a male child protection worker to resist such ideals both directly - through their interactions and conversations with male and female clients - and indirectly - by virtue of their participation in a form of "female" work, thus combatting myths about "masculine" and "feminine" roles. Moreover, at least one of these co-researchers has taken it upon himself to educate and correct fellow coworkers who possess attitudes that perpetuate male dominance and hegemonic masculinity.

While it is no doubt possible (and beneficial) for female child protection workers to resist gender-based stereotypes and correct damaging and oppressive attitudes held by clients and peers, as explained by these co-researchers, being male placed them in a unique position when interacting with other men and resisting patriarchy within this population. As the male clients in need of guidance on these matters are precisely the ones who possess derogatory attitudes about women and have little respect for those belonging to this gender, acts of resistance (e.g., verbally confronting the damaging attitudes of male clients; educating male clients about the rights of women) by female child protection workers will likely have little impact among this group. However, being a male may afford the child protection worker a strategic advantage in such endeavors; male child protection workers may be more respected by these individuals (and thus be taken more seriously / enable rapport building that can facilitate transformation), and may represent an embodied example of a different type of masculinity - one that is rooted in equality 
and respect, rather than power and the subordination of others. In addition, being male also provides the unique opportunity to dispel oppressive myths in the minds of women, by modeling "male" behavior that runs counter to hegemonic masculinity and its associated ideals (e.g., modeling a more balance power relationship with their female clients; showing female clients what it is like to receive male respect; empowering females to have a voice). When taken together, it can be seen that male child protection workers thus hold a unique and important role in the fight against gendered oppression and masculine ideals that are damaging to men and women alike.

Importantly, it must be pointed out that my own identity may be influencing my interpretation of my findings. For example, as a heterosexual male, I may be biased in how I am interpreting the interactions of these male child protection workers with their female clients. Moreover, as a white male, I may have difficulty identifying how race could play into the processes and interactions of male child protection workers. As such, while I have done my best to keep my own biases in tact, there is always the possibility that my positionality may affect my research conclusions. Additionally, it also important to note that the opinions and perceptions of the co-researchers themselves may reflect their own positionality as male child protection workers of particular races, sexualities, and socioeconomic statuses within a patriarchal hegemonic society. As such, their interpretations of reality may too be biased. In order to ensure that the experience of male social workers is not essentialized, as elaborated upon below it is critical to pursue similar research questions in the future research drawing upon perspectives of multiple parties of varying identities.

Future Research 
While a number of interesting insights were revealed though my discussions with these male child protection workers, several avenues for future research can be suggested, some of which are based on the limitations of this MRP. First, future research may wish to expand upon this inquiry by incorporating the perspectives and experiences of males possessing more diverse social identities. As an example, the men in my study were all Caucasian. As such, future research could benefit from interviewing males who also belong to other racial groups. Moreover, hearing the stories of gay or queer male child protection workers may contribute to an even richer analysis and better understanding of how the intersection of identities may impact the experiences of males within this field. One of the male child protection workers interviewed in this study also explicitly made reference to how "his age and being a guy" impacted his interactions with others, thus suggesting that this demographic characteristic may also be of relevance when examining relations of power within this field. In line with critical masculinity theory, there are indeed multiple masculinities that exist within society (Connell, 1995). As such, expanding this investigation to better reflect the diversity within the male gender will be of paramount importance moving forward. This may be especially critical given that males possessing other minority identities may face unique and especially strong barriers, given their relative position of subordination within the gender hierarchy among men.

Second, while the current study has drawn on the perspectives of male child protection workers, future research may also wish to investigate the issues examined in this MRP using the voices of clients who are receiving service from male workers. While it is no doubt critical to capture the personal views of male child protection workers themselves, it remain possible that caregivers and children may see interactions with male child protection workers differently, or could draw attention to dynamics and challenges that would not otherwise be recognized. If 
researchers wish to gain knowledge about how being a male impacts relationships between workers and their clients, a more holistic understanding can only be achieved if the opinions and experiences of clients themselves, are also sought out. Similarly, as this MRP was also interested in the dynamics between male child protection workers and their fellow colleagues, future research could benefit from discussions with female child protection workers themselves. More specifically, female employees could contribute more to the discussion of how the presence of male child protection workers impacts the service provided by their agencies, the relationships between themselves and these male workers, and whether they see patriarchal dynamics occurring in the workplace, such as those revealed in this study.

Third, it is important to point out the possibility that male child protection workers who have faced significant and/or extreme professional challenges given their gender, may in fact, have left the child protection profession all together. As such, it remains possible that the male child protection workers that are available to interview, do not reflect the full spectrum of challenges that may exist for men in this field. Moreover, these individuals may have left to pursue jobs or positions that afford them more power and control within the agency, and are thus more "masculine" according to hegemonic ideals. As such, there may be value in speaking to male social workers holding management or supervisory positions within the field of child protection. This is especially important when considering if / how patriarchy is being expressed and perpetrated within this field.

Fourth, future research may also wish to consider how researchers' identities may impact the results obtained. In line with critical masculinity theory, as there exists a hierarchy among males, one possibility may be that damaging power imbalances arise, when male interviewers possess characteristics that are more aligned with the patriarchal social system (for example men 
who is white and heterosexual), compared to those they are interviewing (for example men who is Aboriginal and two spirited). If such a dynamic were to exist between researchers and coresearchers, the latter may not feel as free to openly disclose their unique struggles, for fear of being perceived as less masculine. While likely not an issue in the current case given the shared race, sexuality, educational level, and (for the most part) age between myself and the male child protection workers I interviewed, those conducting future research on this topic should nonetheless be aware of, and take these dynamics into consideration.

Finally, future research should consider ways that male child protection workers can be supported in their resistance against patriarchal norms and stereotypes, and learn more about the conditions that facilitate this goal. More specifically, future research should speak with male workers about particular resources that they may find helpful when challenging clients about their hegemonic masculine views (e.g., implementing a mentorship program) and what systemic factors either assist or detract from their efforts to educate males and females (e.g. individual vs. group case management). Furthermore, based on the story shared by one co-research, it is clear that not all male child protection workers share similar motivations for resistance, or even attitudes concerning gender equality. As such, it may also be useful to have male child protection workers who do have this goal, to share their thoughts about the steps that the larger organization could take (e.g. organization-wide sensitivity training; training on issues pertaining to gender, gender roles, and gender identity) in the fight against hegemonic masculinity. By providing a medium through which male child protections workers can communicate their own ideas about how their workplace circumstances could be improved, future research could help prevent the replication and reproduction of patriarchal ideals in the field of child protection. 


\section{Chapter VI : Conclusion}

This MRP explored the experiences of male social workers working within the female dominated profession of child protection. More specifically, it was the goal of this research to determine how masculinity is experienced and enacted within this context, by exploring both the challenges associated with this work, and opportunities for resistance that being a male child protection worker presents. Using the narrative approach I was able to capture the lived and unique experiences of 3 male workers, getting a glimpse into their everyday workplace experiences.

The results of this study reveal the existence of challenges, privileges, and unique possibilities that being a male in a female-dominated profession affords. Insights have been gained into not only the existence of hegemonic masculine ideals within this context, but their damaging role when it comes to the interactions that male child protection workers have with their clients and coworkers. Moreover, patriarchal gender roles and stereotypes at times impact how these men are viewed by those in the social environment, often in negative ways. How patriarchy seeps into our institutions, even those that are attempting to fight against social injustice and inequality, is an important take-away from this research. Importantly, through their counter-normative role, the actions, attitudes and goals of these male child protection workers also highlight a previously unacknowledged avenue through which gender oppression on a larger social scale can be addressed. As such, this project not only reveals the lived experiences of male child protection workers - and the role of hegemonic masculinity in these experiences - but also contributes insights that can be used to combat gender oppression and patriarchy more generally. In so doing, it is my hope that this MRP can contribute to critical, transformative AOP practice. 


\section{Appendix A}

\section{RYERSON}

UNIVERSITY

Male social worker: The experience of masculinity in women's work

Your assistance with a study being conducted by Mr. Michael Dionisi (MSW Candidate) Ryerson University - is being requested. To participate in this study you MUST a) be a male social worker; b) be currently employed (full-time; part-time) in child protection; c) be working in a frontline role (i.e. family service, intake, child protection worker); AND d) be 18 years of age or older.

This study involves discussing the experiences and challenges associated with being a male social worker in a female-oriented field of work. This study will involve a 30-45 minute, one-onone interview to be conducted outside of working hours, at an agreed upon time and location (i.e. local library). Although you will be asked several specific questions, the majority of the interview will be participant-directed. In other words, you will be controlling what is discussed. Please note that as part of this process, some sensitive issues may arise. With that said, you do not have to respond to anything that makes you uncomfortable, and you are free to stop participating at any time.

Please be reminded that participation in this study is entirely voluntary. Your decision to participate or not participate will have no bearing on your current or future employment. This study is not sponsored by your organization, and no one from your organization will be made aware of your participation should you choose to be involved in this study.

Be advised that this study has been reviewed and approved by the Ryerson Ethics Board.

If you have any questions, or you are interested in participating, please contact me (michael.dionisi@ryerson.ca) for more information and/or to set up an interview time.

Sincerely,

Mr. Michael Dionisi, Ryerson University

michael.dionisi@ryerson.ca 


\section{Appendix B}

\section{Tests, Questionnaires, and Interview Guides}

1. How did you choose the field of social work?

2. What have your experiences been like working in child protection?

3. How do you think the public views male social workers? Why?

4. How do you feel that being a man has affected your work?

5. Does being a man in your profession affect your interactions with clients?

6. Does being a man in your profession affect your interactions with coworkers?

7. Do you think being a man is an advantage or disadvantage in frontline social work? Why or why not?

8. How has your job affected the way you feel about yourself/yourself as a man?

9. How has the public's perception of masculinity / what is means to be a man, affected your work?

10. How has affected how you define "manliness"?

11. Do you feel the need to engage in certain pastimes or activities after work, because of your experiences at work? 


\section{Appendix C \\ CONSENT LETTER}

\section{Male social worker: The experience of masculinity in women's work}

You are being asked to participate in a research study. Before you give your consent to be a volunteer, it is important that you read the following information and ask as many questions as necessary to be sure you understand what you will be asked to do.

\section{Investigators:}

This study is being conducted by Michael Dionisi, a MSW Candidate at Ryerson University's School of Social Work

\section{Purpose of the Study:}

The purpose of this research is to discuss the experiences and challenges associated with being a male social worker in a female-oriented field of work. To participate in this study you MUST a) be a male social worker; b) be currently employed (full-time; part-time) in child protection; c) be working in a frontline role (i.e. family service, intake, child protection worker); AND d) be 18 years of age or older.

\section{Description of the Study:}

This study will involve a 30-45 minute, one-on-one interview (with myself, Mr. Michael Dionisi) to be conducted outside of working hours, at an agreed upon time and location that the participant is comfortable with (i.e. local library). Although you will be asked several specific questions pertaining to your work experiences with clients and coworkers, and your male identity, the majority of the interview will be participant-directed. In other words, you will be controlling what is discussed. Please note that as part of this process, some sensitive issues may arise. With that said, you do not have to respond to anything that makes you uncomfortable, and you are free to stop participating at any time.

\section{What is Experimental in this Study:}

None of the procedures used in this study are experimental in nature. The only experimental aspect of this study is the gathering of information for the purpose of analysis.

\section{Risks or Discomforts:}

There are potential risks to participation including social risks (e.g., speaking about co-workers) and legal risks (e.g., discussion about clients). As you will be reflecting on your personal experiences, which at times may be uncomfortable, there may also be psychological risks. Importantly, these risks will be managed through various measures. First, several support resources containing information on mental health and the rights of employees, along with contact numbers to be used to obtain support if needed (e.g., help centers, counselors) will be provided to you. Second, you are not required to speak about any of the topics you are uncomfortable with, and you can also stop participation at any time without consequence (see below). This study is confidential and anonymous; your name or organization affiliation will not be used or identified. No one from your organization or personal life will know you have chosen to participate (or not participate) in this study. This study is not being run by your organization. Third, given the methodology used, you will have full discretion / are able to steer the discussion 
in the manner you wish, and hence control the conversation. You also have the opportunity to review the transcripts following the interview and prior to submission of the final research draft to ensure the information recorded is accurate and representative.

\section{Benefits of the Study:}

The aim of this study is to bring to light and give voice to the experiences / obstacles of men working within the field of social work, particularly that of child protection. Thus my research may provide you with a voice and forum to express yourself, and share your unique insights and experiences about working within a female dominated workplace. I cannot guarantee, however, that you will receive any benefits from participating in this study.

\section{Confidentiality:}

Your confidentiality will be protected in several ways. First, no one from your workplace or personal life will be made aware of your participation. Second, minimal descriptors of your workplace (i.e. large rural child protection agency) will be used. Third, interviews will be conducted outside of your workplace and working hours, to maintain your privacy and so that you do not have to reveal participation through work absence. Only the primary investigator (Mr. Michael Dionisi) and his academic supervisor (Dr. Henry Parada) will have access to the collected data. Collected data will be stored on an encrypted memory card, and on an encrypted, password-protected computer for a period of 2 years, after which time it will be deleted.

\section{Incentives to Participate:}

There is no compensation associated with participation in this research.

\section{Costs and/or Compensation for Participation:}

The only costs associated with participation in this study pertain to the travel costs you will incur getting to and from the location where the interview will be held. However, attempts will be made to insure this location is convenient and close to you.

\section{Voluntary Nature of Participation:}

Participation in this study is voluntary. Your choice of whether or not to participate will not influence your future relations with Ryerson University or your place of employment. If you decide to participate, you are free to withdraw your consent and to stop your participation at any time without penalty or loss of benefits to which you are allowed. At any particular point in the study, you may refuse to answer any particular question or stop participation altogether.

Questions about the Study: If you have any questions about the research now, please ask. If you have questions later about the research, you may contact.

PI/Study Coordinator

Telephone Number (work phone - do not include your home phone number). 
If you have questions regarding your rights as a human subject and participant in this study, you may contact the Ryerson University Research Ethics Board for information.

\section{Toni Fletcher \\ Research Ethics Coordinator \\ OVPRI}

1 Dundas Street West, 11th Floor

Toronto, Ontario M5G 1 Z3

(416)979-5000 ext. 7112

toni.fletcher@ryerson.ca

\section{Agreement:}

Your signature below indicates that you have read the information in this agreement and have had a chance to ask any questions you have about the study. Your signature also indicates that you agree to be in the study and have been told that you can change your mind and withdraw your consent to participate at any time. You have been given a copy of this agreement.

You have been told that by signing this consent agreement you are not giving up any of your legal rights.

Name of Participant (please print)

Signature of Participant

Date

Signature of Investigator

Date

For the purpose of accuracy, this interview will be audio recorded. By signing below, you provide consent to be audio recorded. Recordings will be kept confidential, and only be used for the purpose of this study.

Name of Participant (please print)

Signature of Participant

Date

Signature of Investigator

Date 


\section{References}

Andrews, M., Stewart, N., Morgan, D., \& D’Arcy, C. (2012). More alike than different: A comparison of male and female RNs in rural and remote Canada. Journal of Nursing Management, 20, 561-570.

Arntz, J., Arntz, B., \& Petterson, I. (2007). Violence in the nursing profession: Occupational and lifestyle risk factors in Swedish nurses. International Journal of Work, Health, \& Organisations, 10(2), 119-127.

Ashraf, M. (2007). Factors affecting female employment in male-dominated occupations: Evidence from the 1990 and 2000 census data. Contemporary Economic Policy, 25(1), 119-130.

Beggs, J, \& Doolittle, D. (1993). Perceptions now and then of occupational sex typing: A replication of Shinar's 1975 study. Journal of Applied Social Psychology, 23(17), 14351453.

Bem, S. L. (1981). Bem sex-role inventory: Professional manual. Palo Alto, CA: Consulting Psychologists Press.

Berdahl, J. L., Magley, V. J., \& Waldo, C. R. (1996). The sexual harassment of men?. Psychology of Women Quarterly, 20(4), 527-547.

Cejka, M. A., \& Eagly, A. H. (1999). Gender-stereotypic images of occupations correspond to the sex segregation of employment. Personality and social psychology bulletin, 25(4), 413-423.

Chilisa, B. (2012). Whose reality counts? Research methods in question. In Indigenous research methodologies (pp. 73-96). Los Angeles: SAGE. 
Christie, A. (2001). Men and social work: Theories and practice. Basingstoke, England: Palgrave.

Connell, R.W. (1995). Masculinities. Cambridge: Polity Press.

Connell, R.W. (2000). The men and the boys. London: Polity.

Courtenay, W. (2000). Constructions of masculinity and their influence on men's well-being: A theory of gender and health. Social Science and Medecine, 50, 1385-1401.

Fiske, S. T., \& Glick, P. (1995). Ambivalence and stereotypes cause sexual harassment: A theory with implications for organizational change. Journal of Social Issues, 51(1), 97-115.

Fottler, M. (1976). Attitudes of female nurses toward the male nurse: A study of occupational segregation. Journal of Health and Social Behavior, 17(2), 98-110.

Fraser, H. (2004). Doing narrative research: Analysing personal stories line by line. Qualitative Social Work, 3, 179-201.

Gillingham, P. (2006). Male social workers in child family welfare: new directions for research. Social work, 51(1), 83-85.

Glick, P. (1991). Trait-based and sex-based discrimination in occupational prestige, occupational salary, and hiring. Sex Roles, 25, 351-378.

Glick, P., Wilk, K., \& Perreault, M. (1995). Images of occupations: Components of gender and status in occupational stereotypes. Sex roles, 32(9-10), 565-582.

Heilman, M. E. (2012). Gender stereotypes and workplace bias. Research in Organizational Behavior, 32, 113-135.

Hick, J. (2012). An exploratory study of women in Ghana's accountancy profession. Gender and Behaviour, 1(4), 589-609. 
Hsu, H-Y., Chen, H-Y., Yuh, S-H., \& Lou, J-H. (2010). Job stress, achievement motivation and occupational burnout among male nurses. Journal of Advanced Nursing. 66, 1592-1601.

Kimmel, M., 1995. Manhood in America: A Cultural History. Free Press, New York.

Larsson, S., \& Sjöblom, Y. (2010). Perspectives on narrative methods in social work research. International Journal of Social Welfare, 19, 272-280.

Loughrey, M. (2008). Just how male are male nurses? Journal of Clinical Nursing. 17, 13271334.

Lupton, B. (2006). Explaining men's entry into female-concentrated occupations: Issues of masculinity and social class. Gender, Work and Organization, 13(2), 103-128.

Mansfield, P. K., Koch, P. B., Henderson, J., Vicary, J. R., Cohn, M., \& Young, E. W. (1991). The job climate for women in traditionally male blue-collar occupations. Sex Roles, 25(12), 63-79.McMillian, J., Morgan, S., \& Ament, P. (2006). Acceptance of male registered nurses by female registered nurses. Journal of Nursing Scholarship. 38, 100-106.

Meadus, R., \& Twomey, C. (2001). Men student nurses: The nursing education experience. Nursing Forum, 46(4), 269-279.

Migliaccio, T. (2009). Men's friendships: Performances of masculinity. The Journal of Men's Studies, 17(3), 226-241.

Murray, S. (1996). "We all love Charles": Men in child care and the social construction of gender. Gender and Society, 10(4), 368-385.

Newhill, C. (1996). Prevalence and risk factors for client violence towards social workers. Family in Society, 77(8), 488-495. 
Parrott, D. J. (2009). Aggression toward gay men as gender role enforcement: Effects of male role norms, sexual prejudice, and masculine gender role stress. Journal of personality, 77(4), 1137-1166.

Pleck, J. H. (1981). The myth of masculinity. Cambridge, MA: Mit Press.

Poole, M., \& Isaacs, D. (1997). Caring: A gendered concept. Women's Studies International Forum, 20, 529-536.

Potts, K., \& Brown, L. (2005), Becoming an anti-oppressive researcher. In L. Brown \& S. Strega (Eds.), Research as Resistance (pp. 255-286). Toronto: Canadian Scholars' Press.

Rajacich, D., Kane, D., Williston, C., \& Cameron, S. (2003). If they do call you a nurse, it is always a "male nurse": Experiences of men in the nursing profession. Nursing Forum, 48, 71-80.

Ringstad, R. (2005). Conflict in the workplace: Social workers as victims and perpetrators. Social Work, 50(4), 305-313.

Rudman, L.A. (1998). Self-promotion as a risk factor for women. The costs and benefits of stereotypical impression management. Journal of Personality and Social Psychology, 75, 629-645.

Scott-Samuel, A., Stanistreet, D., \& Crawshaw, P. (2009). Hegemonic masculinity, structural violence and health inequalities.

Shinar, E. H. (1975). Sexual stereotypes of occupations. Journal of Vocational Behavior, 7(1), 99-111.

Smith, L. (2013). Working hard with gender: Gendered labour for women in male dominated occupations of manual trades and information technology (IT). Equality, Diversity, and Inclusion, 32, 592-603. 
Soerlie,V., Talseth, A., \& Norberg, A. (1997). Male nurses-reasons for entering and experiences of being in the profession. Scandinavian Journal of Caring Sciences, 11, 113-118.

Sumsion, J. (1999). Critical reflection on the experiences of a male early childhood worker. Gender and Education, 11(4), 455-468.

Tankha, G. (2006). A comparative study of role stress in government and private hospital nurses. Journal of Health Management. 8, 11-22.

Thompson, E., \& Pleck, J. (1986). The structure of male role norms. American Behavioural Scientist, 29, 531-543.

Wedgewood, N. (2009). Connell's theory of masculinity-its origins and influences on the study of gender 1. Journal of gender studies, 18(4), 329-339.

West, C., Zimmerman, D.H., 1987. Doing gender. Gender and Society 1 (2), 125-151.

White, M. J., \& White, G. B. (2006). Implicit and explicit occupational gender stereotypes. Sex Roles, 55(3-4), 259-266.

Whittcock, M. \& Leonard, L. (2003). Stepping outside the stereotype. A pilot study of the motivations and experiences of males in the nursing profession. Journal of Nursing Management. 11, 242-249.

Wood, W., \& Eagly, A. (2002). A cross-cultural analysis of the behavior of women and men: Implications for the origins of sex differences. Psychological bulletin, 128(5), 699.

Yang, C., Gau, M., Shiau, S., Hu, W., \& Shih, F. (2004). Professional career development for male nurses. Nursing and Health Care Management and Policy, 48(6), 642-650.

Zelek, B., \& Phillips, S. (2002). Gender and power: Nurse and doctors in Canada. International Journal of Equity and Health, 2, 1-5. 